Suggestive Therapeutics, and its Apllichtion to Nervous and Mrental Mraludies, to Surgery, Obstetrics, and Pedagogy.

By M. le Dr. A. Cullerre. 'This work, one of a series by the same author, is of special interest to physicians. It is not a mere statement of observations and opinions of physicians who have used this method of treatment. The first part is a brief outline of all questions bearing on suggestive therapeutics, and is an endeavor to reconcile contradictory statements and opinions on hypnotism. The remainder of the book is practical, treating of the indications and effects of suggestive medicine, the chapter on mental maladies being worked out in the most complete form. The book is a marked improvement on that of Schmidkunz, as well as that of Ringier's interesting treatise, and is an excellent addition to the works of Mo1l, Wetterstrand and Forel.

\title{
On the Discrimination of Groups of Rapid Clicks.
}

By Thaddeus L. Bolton (Am. Jour. of Psych., Vol. V. No. 3).

This interesting series of experiments was performed by Mr. Bolton in his endeavor to answer the question, can the presence of one more or one less click be recognized when successive groups of different numbers of clicks are given, and under what condition as to rate and number.

The apparatus is sufficiently simple, consisting of a time marker, the armature of which produces the clicks at the closing of the circuit. The sound at the break was avoided by making the armature react against a piece of soft India rubber. A heavy pendulum, drawing across a series of equal brass plates, two platinum points attached to it at suitable distances apart-one behind the other-produced the regular succession of uniform clicks. These brass plates were separated by pieces of hard rubber of uniform thickness, each plate connected by a separate wire with a switch board, which made it possible to add or subtract one or more clicks by throwing one or more plates out of connection with the time-marker. The platinum points were attached to brass wire springs to avoid retarding the movement of the pendulum, while the switchboard was so arranged as to prevent the pendu$1 \mathrm{~m}$ from touching on the return swing. The apparatus was timed by the writing of the time-marker on a drum 
in conncetion with a Iuprez signal driven by a tuning fork of one hundred vibrations a second.

At first ten clicks were used for the experiments, the clicks being separated by an interval of .or I of a second, the groups by an interval of .25 of a sccond. All numbers from four to ten were uscd as standards, and compared with numbers greater or less by one. As a result of experiments on three subjccts, it was found possible to recognize a difference of one click in any number below ten, with the interval above mentioned, the percentage of errors being greater, the greater the number of clicks, and less difficulty being experienced when the standard was compared with a less number of clicks.

In answer to the principal question to be settled by these experiments, it may be said that number has no influence in the mere perception of discreetness; that a difference of one in ten is less difficult to recognize than a difference of one in five, a conclusion agreeing with the psycho-physic law.

Two other points have some light thrown on them by these experiments. One click more or less in successive groups can be recognized when the number of clicks is not too large or the rate too rapid. It is extremely improbable that any clicks are lost in the perception of a rapid group up to 153 a second.

\section{Experiments on Physiological Memory by Means of the Tuterference of Associations.} No. 3).

By J. A. Bergstrom (Am. Jour. of Psych., Tol. T.,

It is a well known fact that old habits are diffictlt to be orercome, and that fatigue or carelessness will lead us unconsciously to forsake a new for an established method of action. But it is only by experiment that we can determine whether the old habit interferes with the forming of the new one. To decide this problem was the object of the series of cxperiments undertaken by Mr. B.

Unprinted cards wcre made into packs of eighty, each pack containing ten kinds of cards, and each kind having the same abstract word printed at the top, such as "Vitalism," "Homophone," etc.

The experiment consisted in sorting two packs in quick succession, placing cards containing the same word in the same pile, the arrangement of the rrords to be different for the second pack. The length of time required for sorting the second pack was longer in nearly all cases, 